\title{
ESTUDO SOBRE O POLIAMOR NO TEMPERO DO "SABOREARTE" DE DONA FLOR E SEUS DOIS MARIDOS
}

\author{
Edna Raquel Rodrigues Santos Hogemann ${ }^{1}$ \\ Victor Pina Bastos ${ }^{2}$
}

\begin{abstract}
Resumo: Confronta o relacionamento descrito por Jorge Amado na obra Dona Flor e seus dois maridos e as controvérsias que envolvem o poliamor no direito brasileiro sobre temas como a família em si e a autonomia privada dos indivíduos em constituírem família. Valendose da metodologia dialética analítica, tendo como referencial teórico o culturalismo realeano, promove um olhar crítico-reflexivo entre autonomia privada e moral social. Percebe que as questões se travestem de jurídicas, estão imbuídas de valores morais que legitimam a monogamia infiel, mas não o poliafeto leal. Entendendo, por fim, que cabe ao intérprete da norma, encarnar a possibilidade do poliamor ou permanecer na cegueira relacional.
\end{abstract}

Palavras-chave: Poliamor; Monogamia; Família; Autonomia Privada; Moral.

\section{STUDY ABOUT THE POLYAMORY IN THE SEASONING OF THE "SABOREARTE" OF DONA FLOR AND HER TWO HUSBANDS}

\begin{abstract}
It confronts the relationship described by Jorge Amado in the work Dona Flor and her two husbands and the controversies that involve the polyamor in Brazilian law on subjects such as family and private autonomy of the individuals in to constitute. Using the dialectical methodology, the theoretical reference in Realean culturalism, it promotes a critical-reflexive look between private autonomy and social moral. It perceives that the issues are legal, imbued with moral values that legitimize unfaithful monogamy, but not loyal polyamorism. Finally, it understands that it is up to the interpreter of the norm to incarnate the possibility of polyamory or to remain in relational blindness.
\end{abstract}

Keywords: Polyamory; Monogamy; Family; Private Autonomy; Moral.

\footnotetext{
${ }^{1}$ Pós-Doutora em Direito (UNESA-RJ). Doutora em Direito (UGF-RJ). Professora Permanente do Programa de Pós-Graduação em Direito da Universidade Estácio de Sá. Coordenadora do Curso de graduação em Direito da Escola de Ciências Jurídicas da Universidade Federal do Estado do Rio de Janeiro. Membro da Rede Direito e Literatura - RDL e da Law \& Society Association-EUA.

${ }^{2}$ Mestrando em Direito, da Universidade Estácio de Sá, Rio de Janeiro.
} 


\section{INTRODUÇÃO}

As obras de Jorge Amado até hoje trazem questionamentos em diversos aspectos do cotidiano como as liberdades e crenças tradicionais. O presente ensaio levanta os questionamentos que a obra "Dona Flor e seus dois maridos", gerou ao questionar temas que envolvem sexo, casamento, família, escolhas, indivíduos, a sociedade, a moral pública e o Direito. Tais questionamentos se justificam por lidar com elemento basilar da sociedade: a estrutura da família tradicional da sociedade ocidental.

Os autores trabalham com os seguintes questionamentos: Quem nunca se viu diante da escolha entre dois grandes amores? Quem nunca pensou que seria possível? Quem nunca pensou que o poliamor até existe? Seria o poliamor um fato social? Como fatos sociais levam a criação de normas numa feição realeana?

Para responder essas inquietações o artigo foi concebido em três etapas:

A primeira parte da análise do triângulo amoroso desencarnado, de Vadinho, Teodoro e Dona Flor para expor o conflito da monogamia como modelo de família e a realidade dos personagens, bem como entender se há a realização do casal nessa relação contratual de viés liberal burguês, a princípio tão carnal quanto espiritual.

Já na segunda, se é possível encarnar a situação do livro, os autores promovem um questionamento no que diz respeito à visão da monogamia como único sistema legítimo de família, bem como o peso que o Direito dá entre o direito à personalidade e os patrimoniais. Por fim, busca-se entender quais os verdadeiros limitadores para pessoas maiores, capazes e concordes não poderem plenamente constituir família entre si.

A terceira parte trata-se da conclusão, em que se espera encontrar as respostas para as questões legitimadoras (ou não) para o desencarnar ou encarnar do poliamor no direito brasileiro.

Utilizou-se a pesquisa bibliográfica e documental tendo como foco a obra literária de Jorge Amado, bem como instrumentos de coleta de dados, livros, teses, artigos sobre o assunto ou com ele relacionado, sites na internet, reportagens, que contribuam para a busca de conhecimento e para se chegar a uma conclusão a respeito do assunto de como evoluiu e como poderá evoluir a família. 


\section{UM TRIANGULO DESENCARNADO}

Deve-se ficar atento que a história narra as desventuras da personagem Dona Flor. A história já inicia com a protagonista casada com Vadinho, representante da boemia e malandragem, do desejo e da impulsividade. No entanto, Vadinho, em plena vadiagem, morre em dado momento da trama e por ser Dona Flor viúva jovem, as beatas da localidade puseram como meta lhe arrumar novo marido. Tal intromissão quase fez a heroína casar com Eduardo, o "Príncipe", que na verdade era um calhorda que enganava viúvas para roubar-lhes as economias.

Após certo tempo Dona Flor conhece e se casa com Teodoro, o representante da seriedade, o previsível. Ele supre suas necessidades como "ideal" de mulher, contudo, sua parte carnal, diga-se sensual, fica incompleta.

Eis, então, que ressurge Vadinho, que passa o dia e noite tentando-a. Razão pela qual a jovem senhora pudica entra em conflito ao pensar se está traindo um ou o outro, se é possível (legal e correto) ter os dois amores ao mesmo tempo, embora um dos dois seja o marido defunto, mas que lhe literalmente enche de prazer na cama, e o que realmente é a família.

\section{a) Conflito da família monogâmica}

O conflito que afligiu o coração da protagonista é o mesmo que aflige a questão da família do ocidente. Seria mesmo a monogamia o princípio basilar e original das construções familiares?

A sociedade humana tem como base axiológica a reunião de pessoas em comunidade, que deixam de agir individualmente para viver em conjunto. No entanto, as comunidades só teriam conseguido surgir por ter, cultural e antropologicamente, se reunido, originalmente, como família. Essa família é considerada, até hoje, como peça fundamental - e núcleo- da sociedade; não por acaso tem-se que na Constituição Federal do Brasil o constituinte a declara como base social e que tem especial proteção do Estado.

No entanto a noção do que vem a ser o conceito de família tem variado tanto no tempo, quanto no espaço e na cultura. De todo modo, no caminhar da humanidade, os 
primeiros grupos sociais seriam familiares ainda que não com o perfil contemporâneo, mas seus aglomerados geraram clãs, que geraram cidades e nações.

De toda sorte, no decorrer da história as sociedades começam, em geral, a conduzirse pela forma heterossexual monogâmica de família, fazendo com que outra forma de arranjo familiar fosse considerada anormal (homoafetivos) e/ou criminosa (bigamia).

No que concerne à monogamia, Ferrarini (2010, p. 92) em sua obra Famílias simultâneas e seus efeitos jurídicos preleciona "trata-se a monogamia de uma característica histórica-sociológica reconhecida como padrão médio da família ocidental”.

Acontece que mesmo em um sistema monogâmico é possível verificar que muitas pessoas - em geral os homens, por viver-se num mundo ainda de viés patriarcal -, não permanecem totalmente fiéis aos seus companheiros, sendo comuns os relacionamentos paralelos. Razão pela qual, vale destacar que paralelos, mas desiguais, já que tal comportamento é bem melhor aceito para os homens que para as mulheres. Tal apontamento tem como escudeiro as palavras do personagem Vadinho ao afirmar: "Vim impedir que tomasses um amante e arrastasses teu nome e tua honra pela lama" (AMADO, 2008, p.252) . Entretanto, é importante lembrar que em diversas passagens da obra é possível ver o mesmo Vadinho tanto em vida quanto após sua morte, - encarnado e desencarnado - tendo amantes e "gracejando" mulheres.

Engels, ao refletir sobre a institucionalização da família, relata que mesmo na adoção da monogamia, o homem não abandonou totalmente as características poligâmicas, antes presentes na pré-história, adotando a infidelidade ocasional, sendo direito dos homens e motivo de sanção para mulheres (ENGELS, 2016, p. 49). O autor considera que "foi a primeira forma de família que não se baseava em condições naturais, mas econômicas, e concretamente no triunfo da propriedade privada sobre a propriedade comum primitiva, originada espontaneamente. O surgimento da monogamia nada mais é uma sujeição de um sexo pelo outro" (ENGELS, 2016, p. 51). Na esteira do pensamento marxiano, Engels robustece os conceitos ligados às considerações segundo às quais "a primeira divisão de trabalho é a que se fez entre homem e a mulher para a procriação dos filhos", e ainda acresce, assegurando que "o primeiro antagonismo de classes que apareceu na história coincide com o desenvolvimento do antagonismo entre homem e a mulher na monogamia" (ENGELS , 2016, p. 52). .

Aqui, é identificada declaradamente a opressão estabelecida na relação entre homens e mulheres, "sexo feminino sobre o masculino". Um chefe de sociedade mantendo "a mulher, 
os filhos e certo número de escravos", sob suas vontades e poderes era o que se considerava família por povos como os gregos e os romanos. Aparece, então, ao lado da (ou proveniente da) monogamia, o patriarcado, o novo modelo familiar.

Antes de finalizar sua abordagem a respeito da temática família, Engels, que baseia seu trabalho nas pesquisas realizadas por Lewis Henry Morgan, autor de duas obras de grande importância na área, a saber: "Sistemas de consanguinidade e afinidade da família humana" e “A sociedade antiga", torna a referir-se à obra de Morgan, pondo em destaque a seguinte passagem do autor:

\begin{abstract}
"se se reconhece o fato de que a família tenha atravessado sucessivamente quatro formas e se encontra atualmente na quinta forma, coloca-se a questão de saber se esta forma pode ser duradoura no futuro. A única coisa que se pode responder é que a família deve progredir na medida em que progrida a sociedade. (...) A família é produto do sistema social e refletirá o estado de cultura desse sistema. (...) é lícito pelo menos supor que seja capaz de continuar seu aperfeiçoamento até que chegue à igualdade entre os dois sexos." (MORGAN, apud ENGELS, 2016, p. 76)
\end{abstract}

Por outro lado, ao mesmo tempo em que surge a família monogâmica, como seu complemento surgem o adultério e a prostituição feminina, via de regra, como iniciativas próprias do homem. O conflito que se vive aqui é a questão do travestimento da poligamia em monogamia infiel. Impondo aos que queiram viver em poliamor honesto o: 1) ostracismo social, 2) a não proteção civil e 3) o cassetete penal. E daí nasce o medo, nasce o conflito e a decisão impossível de tantas "Donas Flor".

A solução desse conflito talvez venha do diálogo de Vadinho com Dona Flor em que: "Nosso amor, meu bem, pode ser perjuro se quiseres, para ser ainda mais picante, mas é legal, e também o dele, com certidões e testemunhas, não é mesmo? Assim, se somos ambos teus maridos e com iguais direitos, quem engana a quem?” (AMADO, 2008, p.256).

Nesse momento, importante dar voz também à Constituição Federal brasileira, que em seu artigo 226 afirma ser a família a base da Sociedade tendo especial proteção do Estado. Elege, em seus parágrafos, o casamento como o formador da unidade familiar por excelência. Soma-se a isso a autonomia privada e direito fundamental a liberdade sexual e se tem (ou deveria ter) como resultado o dever-poder do Estado de resguardar todas as formas de família e facilitar sua conversão para casamento.

Há diversas famílias, não só os casados heteroafetivos (família tradicional patrimonial), como os homoafetivos, monoparentais e socioafetivas. Tais formações familiares são advindas de escolhas dos indivíduos, e continuando cada uma sendo família. E, em muitas sociedades já houve, e há, relações poligâmicas. Nota-se, que muitas formações 
não contempla o núcleo essencial monogâmico de um casal, mas continua tendo os laços familiares estabelecidos pelo afeto duradouro.

Descortina-se assim que a monogamia não seria um princípio basilar da família, já que a família continua existindo sem ela.

Dona Flor, apesar dos conflitos, chegou ao final, realizada em seus anseios mais personalíssimos. Nas palavras do personagem-fantasma, Vadinho: “Agora, sim, és Dona Flor inteira como deves ser." (AMADO, 2008, p.256). Esse mesmo personagem aceita a situação com naturalidade, entendendo tudo por legal e honesto. "Ele também é teu marido, tem tanto direito quanto eu. Um bom sujeito esse teu segundo, cada vez gosto mais dele" (AMADO, 2008, p.208). Por fim Teodoro, apesar de não explicitarem, nota e aceita as mudanças na esposa e na relação. Abriu mão de seu orgulho para realizar os desejos de esposa. Fato é que "de braço com o marido felizardo" (AMADO, 2008, p.258) demonstra como se satisfaz da sua relação com Dona Flor e da felicidade da amada, sendo-lhe suficiente.

Nesse ponto fica demonstrado que todos os envolvidos no relacionamento vivem muito bem a sua dinâmica, que pertencem ao foro íntimo do casal. Cada um fez suas decisões autonomamente.

Mas será o casamento uma instituição independente da vontade das partes (instituto) ou aproxima-se dos contratos em que a autonomia privada impera?

Rodrigues (2004, p. 20) analisa a instituição do casamento e defende que, na medida em que as regras são impostas pelo Estado, só haveria aos cônjuges a faculdade em aderir, cuja vontade restaria impotente diante dos efeitos automáticos do instituto. Nessa linha de raciocínio, aos que não se encaixam, resta viver à margem da norma.

Uma visão meramente contratualista do instituto do casamento se limita a conceber os diversos efeitos nos âmbitos civil e empresarial, o que torna o terreno do amor/afeto dos particulares um ambiente estéril e controlado. Muito diverso do que se consagraria como direito fundamental a liberdade sexual e ao direito de gerir sua intimidade.

Dworkin (2005, p.27) dispõe que o Governo deve-se pautar por dois princípios, quais sejam: Elaborar leis e políticas que garantam o destino de seus cidadãos; e que esse destino seja sensível as opções que os próprios cidadãos fizeram. Assim, consegue-se ver o Direito regulando e protegendo a vontade das partes, tornando os indivíduos responsáveis e conscientes das suas próprias escolhas. Dando um patamar mais elevado à realização das pessoas como seres humanos, do que uma segurança jurídica abstrata que esteriliza a amplitude do que é família. 


\section{b) Monogamia ainda é a única via?}

Talvez isso tenha sido respondido no item sobre o conflito das famílias monogâmicas, em que a família continua existindo sem a monogamia. No entanto, destaca-se que pouco elucida saber que não é o único, se não conseguir ver de onde veio, onde está e para onde pode ir com a questão da família e a existência fática do poliamor.

Acerca da poligamia, a Revista VEJA trouxe a nota de que a poligamia seria a união reprodutiva de mais de dois indivíduos da mesma espécie, sendo largamente referenciada no Velho testamento da Bíblia, praticada no Oriente Médio, EUA, permitida pelo Alcorão e outros países. ${ }^{3}$

Epistemologicamente o vocábulo poligamia significa "estado do homem casado ao mesmo tempo com diversas mulheres, ou da mulher casada ao mesmo tempo com diversos homens" (NETTO, 2010, p. 430). Varella expõe, no que diz respeito aos aspectos biológicos que: "Na evolução, os animais optaram por duas estratégias básicas: poligamia e monogamia. Ambas têm vantagens e desvantagens ecológicas que o indivíduo precisa avaliar criteriosamente". ${ }^{4}$ Tais questões demonstram que a escolha entre um ou outro se dá pela cultura, e é a cultura que influencia o Direito, logo são seus valores que norteiam o Estado Democrático de Direito. Assim, segundo Miguel Reale, em qualquer fenômeno jurídico, há um "fato subjacente" (fato econômico, geográfico, demográfica, de ordem técnica, etc.), sobre o qual incide um "valor" que confere determinado significado a esse fato, inclinando ou determinando a ação dos homens no sentido de atingir ou preservar certa finalidade ou objetivo; e, finalmente, uma "regra ou norma", que aparece como medida capaz de fazer a integração de um elemento ao outro, ou seja, do fato ao valor. Toda vez que surge uma regra jurídica, a certa medida estimativa do fato, que envolve o fato mesmo e o protege. A norma envolve o fato, e por envolvê-lo, valora-o, mede-o, em seu significado, baliza-o em suas consequências, tutela o seu conteúdo, realizando uma mediação entre o valor e o fato. Nessa esteira, no que diz respeito à proteção dada pela Constituição Federal inegável reconhecer um novo leque de famílias sendo legitimadas, como uniões estáveis e família monoparental, democratizando e legitimando essa tutela (GIRARDI, 2005, p. 32). Fato é que muitas barreiras têm caído, permitindo o reconhecimento pelo Direito de diversas outras formas de

\footnotetext{
${ }^{3}$ Revista Veja. Sociedades poligâmicas são mais violentas, diz pesquisa. São Paulo: Abril, 25/01/2012. Disponível em <http://veja.abril.com.br/noticia/ciencia/poligamia-gera-sociedades-violentas-afirma-pesquisa>. Acesso em: 28.02.2017.

${ }^{4}$ VARELLA, Drauzio, "Evolução do sexo e sobrevivência" http://drauziovarella.com.br/sexualidade/evolucaodo-sexo-e-sobrevivencia/, acesso em 02.04.2017
} 
família. Referente a esse ideal o Ministro Luiz Fux em seu voto na ADI no 4.277/DF, buscou definir quais seriam os requisitos para se ver constituída uma família (fora da moral):

“O que faz uma família é, sobretudo, o amor - não a mera afeição entre os indivíduos, mas o verdadeiro amor familiar, que estabelece relações de afeto, assistência e suporte recíprocos entre os integrantes do grupo. O que faz uma família é a comunhão, a existência de um projeto coletivo, permanente e duradouro de vida em comum. O que faz uma família é a identidade, a certeza de seus integrantes quanto à existência de um vínculo inquebrantável que os une e que os identifica uns perante os outros e cada um deles perante a sociedade. Presentes esses três requisitos, tem-se uma família, incidindo, com isso, a respectiva proteção constitucional". 5

Acerca das Uniões Homoafetivas, Barroso (2016, p. 105-106), ao analisar essa modalidade de família, entende que seria uma restrição injustificada sobre a autonomia em nome de um moralismo impróprio; havendo direitos fundamentais envolvidos (igualdade e liberdade), e não havendo danos a terceiros ou aos próprios, deve o Estado tutelar o exercício do afeto e da sexualidade.

Assim, embasado no amor como o grande definidor do arranjo familiar se torna possível vislumbrar o fenômeno da "união poliafetiva "(ou o poliamor), conceituada por Domith pelo fato de que "Nessa união, todos os seus partícipes, juntos, se considerariam uma família"(2016, p. 1).

Assim, fica claro que há um sem-número de outras vias possíveis, plausíveis e legitimadoras da autonomia das pessoas para realizar suas liberdades e sentimentos de afeto. Busca-se, apenas, guarita do Direito. Importante destacar que, não é porque há uma nova via que as pessoas estão obrigadas a segui-la. Pelo contrário. A ideia é ampliar opções para o escoamento dos amores, não impor novo dogma. Nos dizeres de Vadinho: "Tudo perfeito, meu bem, eu, tu e ele, que mais desejas?" (AMADO, 2008, p.251).

\section{MAIORES, CAPAZES E CONCORDES, PORQUE NÃO?}

O Supremo Tribunal Federal, quando do julgamento da Arguição de Descumprimento de Preceito Fundamental (ADPF) nº 132, avaliou como legítima a interpretação da Constituição que demarca a união estável homoafetiva, muito embora o texto da Carta Maior faça referência às uniões entre homem e mulher, produzindo, de tal modo, mutação constitucional. O sentido cotidiano ou consuetudinário de família não está limitado à

\footnotetext{
5 BRASIL.Superior Tribunal Federal. Ação Declaratória de Arguição de Descumprimento de Preceito Fundamental (ADPF), sob n. ${ }^{\circ}$ 132-RJ. Voto do Mins. Luiz Fux,Brasília, 2011 Disponível em: . <http://redir.stf.jus.br/paginadorpub/paginador.jsp?docTP=AC\&docID=628635> Acessado em: 05.01.2017
} 
concepção de núcleo doméstico pela relação entre casais sissexuais, por ser cogente uma interpretação que não reduza essa noção, que venha a indicar instituição que também se configura por vias outras que não a do casamento civil.

Afiançou a Suprema Corte brasileira o avanço da Constituição Federal de 1988 no plano dos costumes, na direção do pluralismo como categoria sóciopolítico-cultural, que não deve ser obstaculizada pelo padrão binário homemmulher, traçado no seu art. $226, \S 3^{\circ}$. Ora, se a Constituição, nas palavras de seu guardião, não interditou a formação de família por pessoas do mesmo sexo, poderia fazê-lo para limitar seu desenvolvimento a partir da relação entre mais de duas pessoas? (HOGEMANN, 2018, p. 1)

No que diz respeito ao ordenamento infraconstitucional, as relações amalgamadas pelo poliamor, mesmo que com formato diverso ao monogâmico, não têm - nem deveriam ter - impedimento para seu desenvolvimento, desde que não se espraiem pelo âmbito de incidência do princípio da monogamia, que, aparentemente, atém-se ao instituto do casamento, com todas as suas consequências, incluindo a formação de família matrimonial. Isso porque, a o poliamor goza do mesmo alcance de licitude que a união entre pessoas do mesmo sexo, e não suplanta o pressuposto da monogamia, segundo o qual as pessoas adultas possam contrair relacionamentos sexuais e afetivos somente com um parceiro. De sorte que, o princípio da monogamia careceria — se não o faz - guiar as relações matrimoniais , isto é, a união formada pelo casamento nos termos da lei civil, mas não pode constituir óbice às demais formas de união e afeto, por não se mostrar, do ponto de vista biológico, condizente com a natureza humana; nem se revelar, sob o ângulo jurídico, compatível com as diretrizes que a Constituição de 1988 traçou para o Direito das Famílias e, especificamente, para o casamento, sob pena de provocar sérias consequências, inclusive de índole moral, ao forçar os indivíduos a viver contra sua natureza, ontologicamente poligâmica, por razões tradicionais que ocasionariam a marginalização dos indivíduos, na medida em que estabeleceriam suas relações movidos pelo afeto que o Estado não quer reconhecer, apenas para proteger valores com fundamentos suficientemente frágeis para revogar os instintos naturais de procriação.

A ordem jurídica brasileira, ainda que ainda caracterizada pelos ditames dos defensores ferrenhos do princípio da monogamia enquanto vetor legitimador de todas as formas de família, permite entrever as possibilidades jurídicas para legitimação do poliamor ou poliafeto, que, nesse sentido entende-se como consubstanciação da pluralidade afetiva e amorosa, aceite pelo Direito brasileiro na medida em que não encontre vedação legal nem configure crime de bigamia. Afere-se, v.g., os arts. 1.521 , VI e o $1.723, \S 1^{\circ}$, do Diploma 
Civil. Uma leitura combinada desses dois dispositivos — pela utilização de uma interpretação restritiva, na medida em que se tratam de normas limitativas do exercício de direitos subjetivos —, leva a inferir que não se poderão casar as pessoas casadas (art. 1.521, VI) do mesmo modo que não poderá constituir união estável a pessoa casada, salvo se separada de fato ou judicialmente (art. $1.723, \S 1^{\circ}$ ). Importa firmar que, se o ordenamento jurídico brasileiro, de acordo com o princípio da monogamia, proibiu as pessoas formalmente casadas de, nesta condição, casaram-se novamente (Código Penal, art. 235) seja por celebração solene ou pela união estável, permitiu, por derradeiro, que os indivíduos que vivam em união estável, ou queiram fazê-lo, possa, manter mais de um relacionamento simultaneamente, ou venham a firmá-lo com mais de uma pessoa, sendo, no entanto vedada habilitação para casamento stricto sensu (Código Civil, art. 1.511). Do mesmo modo, a lei civil brasileira não cria empecilho àquelas pessoas que venham a casar no decorrer de outra união estável, já que no rol taxativo do artigo 1521, que versa sobre as pessoas impossibilitadas de contrair matrimônio, não se encontra elencado o termo "as pessoas que constituíram união estável". Afinal, não é dado ao analista distinguir situações quando a Lei não o fez nem autorizou que o fizesse.

Outro fator, este de cariz social, deve ser considerado. As relações sociais na pósmodernidade baumaniana, ou na hipermodernidade lypovetskiana, seja como for, caracterizam-se pela individualização superlativa, em que as pessoas têm vivido cada vez mais centradas em si mesmas, relacionando-se à distância e por intermédio de plataformas virtuais. Como pressagiou Bauman, nesse mundo de relações liquefeitas,

\footnotetext{
[o] compromisso com outra pessoa ou com outras pessoas, em particular o compromisso incondicional e certamente aquele do tipo 'até que a morte nos separe', na alegria e na tristeza, na riqueza ou na pobreza, parece cada vez mais uma armadilha que se deve evitar a todo custo (BAUMAN, 2004, p. 111).
}

Razão pela qual, se pode aduzir que a tendência hodierna é a vida individualizada e isolada, reduzido o contato e própria preocupação com o outro, caberia ao Estado, portanto, protetor da família enquanto base social, estimular o cultivo do afeto, da reciprocidade, sem tolher, por formalismos e excessos, todas as formas de amor.

$\mathrm{O}$ afeto deve ser cogitado, em um mundo social que se quer formado pela diversidade. O respeito à diversidade não pode ser visto como algo meramente formal, através de normas ineficazes e frias, distanciadas, pois, da vida real. Ao contrário, o respeito à diversidade perpassa por um comportamento, ou seja, pelo fato de não ver o outro como outro 
em si, mas sim como parte do mesmo. O ordenamento jurídico, no presente contexto, precisa acolher a diferença e a liberdade como pressupostos de elaboração de um discurso e de uma efetivação inclusiva, a partir de uma análise antropológica, dissociada do individualismo.

É certo que o ordenamento pátrio vive um processo de despatrimonialização de seus institutos, através da constitucionalização do fenômeno jurídico, axiologicamente vinculado à dignidade humana. As relações familiares não passam ao largo disso, pautando-se no afeto e não mais em suas repercussões de caráter patrimonial, como dito acima. A partir da releitura do sistema, o afeto é entendido como pré-condição do pensamento e, para SCHELLER, "o ser humano, antes de ser pensante ou volitivo, é um ser amante". (HOGEMANN e SOUZA, 2013, p.84)

Diante das transformações que se apresentam na realidade social envolvendo questões que possuem como amálgama o elemento afetivo, oportunas e precisas as palavras do então Ministro Ayres Brito: “É a perene postura de reação conservadora aos que, nos insondáveis domínios do afeto, [não] soltam por inteiro as amarras desse navio chamado coração". Resta evidenciado, que uma postura conservadora cristalizada pelo legislador através da letra da norma, não mais se adéqua ao tratamento do tema, cabendo, ao poder judiciário, a releitura dos princípios e valores constitucionais, a fim de albergar legitimidade das situações fático-jurídicas que se lhes apresentem e, dessa forma, desprender as amarras e permitir que o navio siga o seu caminho, afinal "navegar é preciso, viver..."

Ao buscar questões impeditivas para a Sociedade de aceitar o poliamor eliminado a questão da capacidade, maioridade, autonomia da vontade e patrimônio, o que sobra para negar?

Desnuda-se as concepções jurídicas neutras, e a balança que a Sociedade apresenta para dizer que é certo ou errado vem da moral, que antes estava travestida de jurídica.

Contrários a visão da poliafetividade estão autores que dizem não são ser possível por:

1) Rogério Greco adverte ser juridicamente conflitante com o ordenamento jurídico pátrio, tornando impossível após o Estado determinar a monogamia, outra forma da família. ${ }^{6}$ Visa proteger a paz social e a base da família ocidental. 2) Por fim, e mais grave, Regina Silva e Alexandre Versignassi consideram a poliafetividade como crime, moralmente degradante para

\footnotetext{
${ }^{6}$ GRECO, Rogério. Curso de Direito Penal: parte especial v. 3. 4. ed. Niterói: Impetus, 2015, p. 619
} 
com a família, afrontando a dignidade das pessoas envolvidas e estimular a violência/desigualdade.

Em contrapartida há os que consideram a poliafetividade como um caminho natural e uma forma de família que merece proteção como todas as outras. O IBDFAM (Instituto Brasileiro do Direito De Família), entende que deve-se reconhecer o outro e suas práticas sociais diversas das nossas, dando igualdade de tratamento para todos os tipos de família.

A união poliafetiva, merece reconhecimento como entidade familiar porque, num primeiro momento, coaduna-se a três princípios fundamentais: o da dignidade da pessoa humana, o da liberdade e o do pluralismo das entidades familiares, pressupostos de tal relevância que não poderiam admitir mitigação pela monogamia. O princípio da liberdade de constituição familiar, que impõe que cada um tem direito de constituir sua união familiar segundo seu querer, não sofrendo limitações ou imposições do Estado ou de qualquer outro ente moral, conduz à conclusão de que o poliafeto é mais uma das hipóteses de exercício da liberdade civil que requer proteção do Estado de duas formas: (i) pelo reconhecimento da legitimidade dessa vontade; (ii) pela proibição de sua intervenção, sob pena de comprometer a tutela ao liberalismo cívico que a própria Constituição deve garantir.

Importante destacar que independente da corrente adotada é inegável a carga valorativa posta e que há pessoas nessa situação familiar. Sendo que as mesmas necessitam a proteção do direito, como também o reconhecimento social. Somam-se também os ensinamentos do professor Miguel Reale (1996, p. 207), em que mostra que os valores e a própria cultura estão sempre mudando de acordo com a história, influenciando e sendo influenciado pelo Direito e seu ordenamento.

O porquê pode ser, em suma, resumido no conflito entre essas duas passagens do livro: "O resto é engano e hipocrisia, por que ainda queres te enganar(...)Vim impedir que tomasses um amante e arrastasses teu nome e tua honra pela lama." ${ }^{\prime 7}$ “. A derradeira chance, Dona Flor, de praticares a virtude, de permaneceres sustentáculo da moral, dos bons costumes. Deixa Vadinho em sua paz de morto, és ou não mulher honesta?" (AMADO, p. 256)

É possível entender que o direito é uma construção cultural. E, a cultura é feita por indivíduos, que por sua vez tem seus valores e morais. Logo, o direito é formado de valores, e se a intenção é aproximá-lo da ideia de "justo", deve-se eliminar a capa da hipocrisia e aceitar

\footnotetext{
${ }^{7}$ AMADO, Jorge. Dona Flor e seus dois maridos. São Paulo: Companhia das letras, 2008, p.256
} 
a liberação do poliamor como uma forma de se viver mais honestamente que a monogamia infiel de hoje. Não se deseja negar ao Estado seu dever de determinar comportamentos de modo a manter a feliz convivência entre os indivíduos que vivem em sociedade. Pretende-se, ao contrário, que exerça sua atividade, primeiramente, por via legislativa, para assegurar que os fenômenos sociais, notadamente aqueles surgidos pelo exercício pleno de liberdade, sejam delimitados adequadamente, para não se transformar em arbítrio nem caos. Não permitir o reconhecimento, como entidade familiar, das uniões afetivas mantidas por mais de duas pessoas - desde que a relação seja consentida, com base no afeto, no respeito mútuo e na preservação da individualidade de cada um dos seus membros — implica negar ao indivíduo o exercício de sua liberdade pelo Estado, rejeição esta que configurará violação manifesta aos princípios da dignidade da pessoa humana e da liberdade. Isso não quer dizer que a formação de famílias afetivas deva ocorrer ao arrepio da lei.

\section{CONCLUSÃO}

A pitoresca história de Dona Flor e seus dois maridos possibilitou ao leitor tomar conhecimento daquilo que pesquisas científicas, realizadas tanto pelo prisma biológico quanto pelo viés antropológico, demonstram: a tendência natural do ser humano de não se restringir ou se submeter a um único parceiro na busca pelo acasalamento, bem como a existência de diversas outras formas de coabitação ao longo da história da humanidade, pondo em xeque as exigências de reverência obstinada à monogamia, cuja desobediência acarretaria, seja a consumação do pecado ou, do rompimento de laços familiares ou da ordem social instituída.

A solução do dilema de Dona Flor - permanecer fiel ao marido vivo e sem graça ou continuar simultaneamente com o romance tórrido com o fogoso fantasma do marido Vadinho -, conforme foi sendo demonstrado no artigo, não está em escolher as opções dadas socialmente, mas em romper com seus pressupostos. Diminuir a interferência da Sociedade na intimidade alheia, romper com a "alma gêmea" e com a monogamia como única via.

Libertando-se dessas correntes não há necessidade dessas escolhas sociais, mas de momentos relacionais. E, tais momentos devem ser decididos em suas intimidades por seus participantes; sendo o Direito a ferramenta necessária para romper essas correntes, para desmarginalizar, e encarnar os direitos fundamentais da liberdade sexual e de autonomia como constituir sua família. 
Assim, após esse passeio literário se pode inferir que o sexo, o casamento e a família, todos eles devem ter por baliza a autonomia da vontade individual e não a "intromissão" de um "Outro" (Estado/Sociedade).

O que lhe dá a verdadeira legitimidade é a aferição da vontade das partes envolvidas, e não da sociedade, que, em verdade, deve se contentar com seu papel de garantidora/respeitadora dos direitos da personalidade de cada um. Importante destacar, assim como o próprio Vadinho e o Teodoro dizem, que essa legitimidade deve vir também pela guarita do Direito (do legal). Por outro lado, esse direito que deve ter como lastro o "afeto", e não o patrimônio ou o olhar alheio. Evoca-se a lembrança da batalha de Vadinho nas páginas finais para legitimar seu triangulo desencarnado, tendo o "amor" vencido à força.

Sustenta-se que o direito deve assumir uma postura pedagógica lúdica e dialógica para a formação de juristas a partir do (re)encontro com seus desejos, abandonando qualquer pretensão de certeza ou de verdade inalterável. A Ciência do Direito precisa ser questionada com Vadinhagem, questionando-se as verdades científicas, abandonando a discussão do "sexo dos anjos". E, sendo percebida como invenção cotidiana, onde não se pode sacrificar o prazer em nome da certeza esterilizante.

Por fim, cumpre destacar que o objeto de reflexão foi o poliamor ou poliafeto como relação possível e fruto da autonomia da vontade livremente exercida, assim como Dona Flor, Vadinho e Teodoro. Permitir não é sinônimo de obrigar. Os argumentos só demonstram que admitir a possibilidade de um poliamor honesto é mais justo, moralmente factível e concatenado com o Ordenamento Pátrio, que continuar apoiando uma monogamia infiel. há de se reconhecer que a solenidade e rigor das relações monogâmicas não acompanha o ritmo acelerado e despojado da fragmentada sociedade do século XXI, época em que as pessoas buscam relacionamentos afetivos com o mínimo de compromisso e responsabilidade possível, como avisou Bauman. Não por acaso, os índices de divórcio, já facilitado legal e burocraticamente no Brasil, estão cada vez mais elevados, demonstrando a preferência pelo isolamento, em detrimento dos votos e ônus que o matrimônio requer exige.

A conclusão não será tão conclusiva, visto a adotar uma visão "a lá Vadinho" de nunca se despedir, estando sempre aberta a novas perspectivas, diálogos e experiências. Após o que foi escrito, as alternativas postas poderão ir no sentido de habilitar o Direito em encarnar a família do poliamor ou relegá-la ao desencarnado literário. Sendo que, relegar significa continuar oculto dos olhos jurídicos, mas tão sentido (e vivido) nos becos e ruas do país. 


\section{REFERENCIAS}

BAUMAN, Zygmunt. Amor líquido: sobre a fragilidade dos laços humanos. Rio de Janeiro: Jorge Zahar, 2004.

BRASIL. Constituição da República Federativa do Brasil (1998). DOU, Brasília, DF, 05 out. 1988.

Disponível em:

http://www.planalto.gov.br/ccivil_03/Constituicao/Constituicao.htm>. Acesso em: 04.12. 2016.

Superior Tribunal Federal. Ação Declaratória de Arguição de Descumprimento de Preceito Fundamental (ADPF), sob n. ${ }^{\circ}$ 132-RJ. Voto do Mins. Luiz Fux,Brasília, 2011 Disponível em:

<http://redir.stf.jus.br/paginadorpub/paginador.jsp?docTP=AC\&docID=628635> Acessado em: 05.01.2017

ACESSÓRIA IBDFAM,Escritura reconhece união afetiva a três <http:// www.ibdfam.org.br/novosite/imprensa/noticias-do-ibdfam/detalhe/4862>. Acesso em: 26.12.2016

AMADO, Jorge. Dona Flor e seus dois maridos. São Paulo: Companhia das letras, 2008.

BARROSO, Luís Roberto. A dignidade da pessoa humana no direito constitucional contemporâneo: a construção de um conceito jurídico à luz da jurisprudência mundial. Belo Horizonte, Fórum, 2016.

COLAVITTI, Fernanda. O Fim da Monogamia? Revista Galileu. Editora Globo, out. 2007.

DOMITH, Laira Carone Rachid. "Lutemos, mas só pelo direito ao nosso estranho amor" - da legitimidade da família poliafetiva. Disponível em: . Acesso em: 29 dez. 2016.

DWORKIN, Ronald, A Virtude Soberana: a teoria e prática da igualdade. Trad. Jussara Simões. São Paulo: Martins Fontes, 2005.

ENGELS, Friedrich. A origem da família, da propriedade privada e do Estado. $15^{\mathrm{a}} \mathrm{ed}$. Rio de Janeiro: Bertrand Brasil, 2016.

FERRARINI, Letícia. Famílias simultâneas e seus efeitos jurídicos: pedaços da realidade em busca da dignidade. Porto Alegre: Livraria do Advogado Editora, 2010.

FILHO; Rodolfo Pamplona; GAGLIANO, Pablo Stolze. Novo curso de Direito Civil: as famílias em perspectiva constitucional. Vol. 6. $4^{\mathrm{a}}$ ed. São Paulo: Saraiva, 2014.

GIRARDI, Viviane. Famílias contemporâneas, filiação e afeto. A possibilidade jurídica da adoção por homossexuais. Porto Alegre: Livraria do Advogado, 2005.

GRECO, Rogério. Curso de Direito Penal: parte especial v. 3. 4. ed. Niterói: Impetus, 2015, p. 619.

HOGEMANN, Edna Raquel e SOUZA, Thiago Serrano Pinheiro de. O direito fundamental ao afeto, in Revista Interdisciplinar de Direitos Humanos, UNESP, v.1., n.1, 2013. Disponível em: http://www2.faac.unesp.br/ridh/index.php/ridh/article/view/155. Acesso em 01 ago 2018.

KANT, Immanuel. “Kritik der Sitten”, Frankfurt: Suhrkamp, 1985. 
KAYSER, Pierre, La protection de La vie pricée, T.1, Protection du secret de la vie privée, Revue Internationale de droit compare, Presses universitaires d'Aix-Marseille ; Ed.3, vol 1, Paris , 1995. NETTO, José Oliveira. Dicionário Jurídico Universitário: terminologia jurídica e latim forense. 4. ed. Leme: EDIJUR, 2010.

OTERO, Cleber Sanfelici; SILVA, Nilson Tadeu Reis Campos. Direitos fundamentais e justiça têm limites? Poligamia e a questão da publicização do privado. In SIQUEIRA, Dirceu Pereira; AMARAL, Sérgio Tibiriçá. (org.) Direitos humanos: um olhar sob o viés da inclusão social. Birigüi: Boreal, 2014.

REALE, Miguel. Filosofia do direito. 17. ed. São Paulo: Saraiva, 1996.

REVISTA VEJA. Sociedades poligâmicas são mais violentas, diz pesquisa. São Paulo: Abril, 25/01/2012. Disponível em < http://veja.abril.com.br/noticia/ciencia/poligamia-gerasociedades-violentas-afirma-pesquisa>. Acesso em: 28.02.2017.

RODRIGUES, Silvio. Direito Civil vol. 6, 28ª ed., São Paulo, Saraiva, 2004.

SARTRE, Jean-Paul. Entre quatro paredes, $3^{\text {a }}$ ed Rio de Janeiro: Civilização Brasileira, 2007.

SILVA, Regina Beatriz Tavares da. "União poliafetiva" é um estelionato jurídico. Disponível em: http://www.reginabeatriz.com.br/academico/artigos/artigo.aspx?id=338 . Acesso em: 27.12.2016.

VALENTE, Ana Lúcia Eduardo Farah. O poliamorismo e a possibilidade de união poliafetiva < https://arpen-sp.jusbrasil.com.br/noticias/100163131/artigo-o-poliamorismo-ea-possibilidade-de-uniao-poliafetiva-por-ana-lucia-eduardo-farah-valente>. Acesssado em: 28 de dez. 2016

VARELLA, Drauzio, "Evolução do sexo e sobrevivência" http://drauziovarella.com.br/sexualidade/evolucao-do-sexo-e-sobrevivencia/, acesso em 02.04.2017

VERSIGNASSI ,Alexandre, E se... não existisse a monogamia?, Revista SuperInteressante, 30.11.2008<http://super.abril.com.br/saude/e-se-nao-existisse-a-monogamia/> Acesso em: 12.01.2017

WALD, Arnold. Curso de Direito Civil Brasileiro: O Novo Direito de Família. São Paulo: Saraiva, 2004. 